\title{
Ishak Score
}

National Cancer Institute

\section{Source}

National Cancer Institute. Ishak Score. NCI Thesaurus. Code C95149.

A scoring system described by Dr. Ishak and colleagues that assesses the histopathologic degree of liver damage. 